\title{
Association between Body Mass Index and Gastroesophageal Reflux Symptoms in Nepalese Adult Population- A Single Centered Hospital Based Study
}

\author{
Akhilesh Kumar Kasyap ${ }^{1}$, Shiv Kumar Sah $^{2}$, Sitaram chaudhary ${ }^{1}$, Ramila Shrestha ${ }^{1}$, Dinesh Shrestha ${ }^{1}$ \\ ${ }^{1}$ National Academy of Medical Science, Bir Hospital Mahabaudha, Kathmandu, Department of Medi- \\ cine, Gastroenterology unit \\ ${ }^{2}$ Little Buddha College of Health Science, Minbhawan, Kathmandu, Faculty of Pharmacy, Purbanchal \\ University
}

Correspondence
Dr. Akhilesh Kumar Kasyap
National Academy of Medical
Science, Bir Hospital,
Mahabaudha, Kathmandu
Department of Medicine
(Gastroenterology unit)
Email:
drakhileshkasyap@gmail.com

DOI: http://dx.doi.org/10.3126/ jcmsn.v11i2.13672

\begin{abstract}
Background \& Objectives: Gastroesophageal reflux disease (GERD) is a common disorder, and studies have reported inconsistent association between high BMI and its elevated risk of GERD symptoms. The aim of the present study was to estimate the strength of the association between body mass index and reflux symptoms in Nepalese adults. Materials \& Methods: This was a cross-sectional study conducted at National Academy of Medical Science, Bir Hospital, Kathmandu, Nepal. All patients of age 18 years or above who underwent endoscopy and diagnosed to have esophagitis were recruited for the analysis. Symptoms were identified by using a self-administered validated questionnaire regarding GERD that identify the onset for GERD symptoms and grade the frequency and severity of symptoms experienced over a period of one year. BMI data, the cut off points were based on the WHO classification of overweight and obesity. A BMI value $\square 25-30$ represents overweight and $\mathrm{BMI}>30$ indicates obesity. A BMI value $<25$ is considered as normal. Severity of erosive esophagitis was graded according to the Los Angeles classification. Results: The Among 127 enrolled esophagitis subjects, about $43 \%$ were under $20 \mathrm{BMI}, 43 \%$ overweight and about $24 \%$ were obese. Obesity measured by BMI revealed no significant association among age, sex, smoker, alcoholics, hernia and severity grade of esophagitis $(p>0.05)$. Ages with various categories $(18-40,>40-60,>60)$ were significantly associated with the GERD symptoms $(\mathrm{P}=0.021)$. We categorize BMI in three categories. A BMI value $<25$ (normal), $\square 25-30$ (overweight), and BMI $>30$ (obesity). Categorical analysis of BMI with GERD symptoms confirmed the absence of any tendency towards an association $(\mathrm{p}>0.05)$. Conclusion: The tendency of reflux symptoms towards BMI is null, and weight reduction may not be the adequate justifiable for the symptoms therapy.
\end{abstract}

Key words: Body mass index, GERD, Obesity

Citation: Kasyap AK, Sah SK, Chaudhary S, Shrestha R, Shrestha D. Association between Body Mass Index and Gastroesophageal Reflux Symptoms in Nepalese Adult Population- A Single Centered Hospital Based Study. JCMS Nepal. 2015;11(2):23-26.

\section{INTRODUCTION}

Gastrointestinal reflux symptoms are common disorder that are associated with the obesity, affecting up to $60 \%$ of individuals at some time during the course of a year and $20 \%-30 \%$ of individuals at least weekly. ${ }^{1,2}$ Gastro-esophageal reflux disorders (GERD) are common in Western countries and has been reported to be increasing in the East. Prevalence of GERD in the prevalence of GERD among Nepalese residing in Brunei
Darussalam was $7.2 \% .{ }^{3}$ Overall $45.1 \%$ had reported symptoms of gastroesophageal reflux: heartburn and regurgitation $(21.4 \%)$, heartburn alone $(9.2 \%)$ and regurgitations alone $(14.5 \%){ }^{3}$ Frequent or severe GERD symptoms are associated with work loss ${ }^{4}$ impaired health-related quality of life, ${ }^{5}$ and esophageal adenocarcinoma, ${ }^{6}$ further emphasizing the clinical significance of this entity.

There is a widespread notion that obese persons are more likely to develop gastro-oesophageal reflux 
disease than leaner subjects, and obese patients who seek medical care for symptoms suggestive of reflux are often recommended by clinicians to reduce their body weight to relieve the symptoms. Some but not all studies have shown that high BMI is associated with an elevated risk of GERD symptoms (e.g., heartburn and/or regurgitation). At least four previous population-based cross-sectional studies found positive associations between overweight or obesity and GERD symptoms in the United States, UK, Norwegian, and Spanish populations. ${ }^{3,7,10}$ In contrast, two other large population-based studies from Sweden and Denmark found no such association. ${ }^{9,11}$ To date, no study has been attempted illustrating the relationship between body mass and symptom of GERD in Nepalese population. Given the importance of body mass and symptoms associated with GERD, in this study we examined the association between body mass and GERD symptoms implying the broader range of BMI categories among the adults with varying severity of the disease.

\section{MATERIALS AND METHODS}

Setting and study design: This was a crosssectional study conducted at National Academy of Medical science, Bir Hospital, Kathmandu, Nepal. All age group of 18 years or above who underwent endoscopy and diagnosed to have esophagitis were recruited for the study. Symptoms were identified by using a self administered questionnaire regarding GERD that identify the onset for GERD symptoms and grade the frequency and severity of symptoms experienced over a period of 1 year. $^{12}$ Sociodemographic and additional information from the GERD including height, weight, tobacco, smoking and family history of GERD.

Body mass index (BMI), a validated measure of body mass independent of height was calculated as body weight divided by the square of body height in meters $(\mathrm{kg} / \mathrm{m} 2)$.

\section{Symptoms evaluation and definition:}

Overweight and obesity: BMI data, the cut off points were based on the WHO classification of overweight and obesity ${ }^{13}$. A BMI value $\square 25-30$ represents overweight and $\mathrm{BMI}>30$ indicates obesity. A BMI value $<25$ is regarded as normal. Severity of erosive esophagitis was graded according to the Los angeles classification ${ }^{14}$.

Statistical analysis: Numerical data were presented as mean \pm SD. The relation between the explanatory and categorical with BMI variables and the dependent dichotomous reflux variable was modeled using Pearson's Chi square test. In analyses of categorized BMI data, the cut off points were based on the WHO classification of overweight and obesity. A BMI value $\square 25-30$ represents overweight and BMI $>30$ indicates obesity. A p value less than 0.05 considered at level of significance. The study protocol was approved by the ethical board of IRB, National Academy of Medical Science (NAMS), Bir Hospital.

\section{RESULT}

A total of 127 patients diagnosed with esophagitis were enrolled for the GERD questionnaire. The mean ages of the subjects were $45.40 \pm 14.74$ years. Proportion of the male patients were $74(58.3 \%)$ and female $53(41.7 \%)$. Mean Body mass index was $26.23 \pm 5.24$. About $43 \%$ of the subjects were under 20 BMI, $43 \%$ overweight and about $24 \%$ were obese. Out of 127 patients, a total of 52 $(40.2 \%)$ patients were reported having smoking while $42(33.1 \%)$ patients being alcoholics. Two patients demonstrated to have peptic ulcer (Table 1).

Table1. Patient's characteristics

\begin{tabular}{|c|c|}
\hline Parameter & Inference \\
\hline No. of patients, $n$ & 127 \\
\hline Age, mean \pm SD ( years) & $45.49 \pm 1.47$ \\
\hline Male, n (\%) & $74(58.3)$ \\
\hline Female, n $(\%)$ & $53(41.7)$ \\
\hline $\mathrm{BMI}$, mean $\pm \mathrm{SD}$ & $26.62 \pm 4.37$ \\
\hline \multicolumn{2}{|l|}{ BMI } \\
\hline$<20$ & $54(42.51)$ \\
\hline $25-30$ & $43(33.85)$ \\
\hline$>30$ & $30(23.62)$ \\
\hline Smoker, n (\%) & $51(40.2)$ \\
\hline Alcoholics, n (\%) & $42(33.1)$ \\
\hline Symptoms present, n (\%) & $112(88.2)$ \\
\hline Symptoms absent, n (\%) & $15(11.8)$ \\
\hline Hiatus hernia, n (\%) & $38(29.9)$ \\
\hline Peptic ulcer, $\mathrm{n}$ & 2 \\
\hline \multicolumn{2}{|c|}{ Loss angel classification, $\mathrm{n}(\%)$} \\
\hline A & $25(19.7)$ \\
\hline $\mathrm{B}$ & $52(40.9)$ \\
\hline $\mathrm{C}$ & $44(34.6)$ \\
\hline $\mathrm{D}$ & $6(4.7)$ \\
\hline
\end{tabular}

We also classified the severity of the disease according to Los Angeles classification, ${ }^{14}$ and were observed that most of the subjects were graded in class B $(40.9 \%$, followed by grade C $(34.6 \%)$, grade A $(19.7 \%)$ and least at grade D (4.7\%). symptoms with esophagitis were predominantly exhibited in $112(88.2 \%)$, while about $12 \%$ were asymptomatic (Table 1). 
Obesity measured by BMI and its association with GERD risk factors are presented in table 2. Different predictors including age $(18-40,>40$ $60,>60)$, sex, smoker, alcoholics, presence of Hernia and severity grade of esophagitis were compared by BMI. We found no statistically significant between the proportion of obesity measured by BMI with the GERD risk factors $(\mathrm{p}>0.05)$.

Distribution of GERD symptoms and potential GERD risk predictors are illustrated in table 3 . We categorize BMI in three categories. A BMI value < 25 (normal), $\square 25-30$ (overweight), and BMI $>30$ (obesity). Categorical analysis of BMI with GERD symptoms confirmed the absence of any tendency towards an association ( $p>0.05)$. Ages with various categories were significantly associated with the GERD symptoms $(\mathrm{P}=0.021)$. Others GERD factors including sex, smoking, alcoholism, hiatus hernia and endoscopic grade showed no tendency of association towards reflux symptoms $(\mathrm{p}>0.05)$

Table 2. Association of obesity, measured by BMI and various GERD risk predictors

\begin{tabular}{|lllll|}
\hline Demographic & \multicolumn{4}{c}{ Body mass index } \\
feature & $<25$ & $25-30$ & $>30$ & P \\
Age & & & & \\
\hline $18-40$ & 13 & 18 & 8 & \\
\hline$>40-60$ & 21 & 21 & 116 & 0.091 \\
\hline$>60$ & 20 & 6 & 6 & \\
\hline Men & 34 & 26 & 14 & \multirow{2}{*}{0.327} \\
\hline Women & 20 & 17 & 16 & \\
\hline Smoker & 24 & 17 & 10 & 0.060 \\
\hline Alcoholics & 19 & 11 & 12 & 0.397 \\
\hline Hiatal hernia & 13 & 16 & 9 & 0.373 \\
\hline Grade & & & & \\
\hline Grade A & 13 & 8 & 4 & \\
\hline Grade B & 22 & 18 & 12 & \\
\hline Grade C & 16 & 15 & 13 & 0.876 \\
\hline Grade D & 3 & 2 & 1 & \\
\hline
\end{tabular}

\section{DISCUSSION}

We demonstrated the clinical association of reflux symptoms with the obesity measured by BMI. Our study revealed no association between BMI and gastro- esophageal reflux symptoms. Our findings are consistent with the previous studies where the finding sought that there was not association between BMI at age 20, BMI 20 years before the interview, or maximum adult BMI and occurrence of reflux symptoms. ${ }^{15}$ One showed no differences in oesophageal $\mathrm{pH}$ compared with normal weight subjects ${ }^{16}$ and the other found no improvement in reflux symptoms or oesophageal $\mathrm{pH}$ after weight reduction. ${ }^{17}$ However, our results are differ from previous study where the obese participants were 2.5 times as likely as those with normal BMI $(<25)$ to have reflux symptoms or esophageal erosions. ${ }^{18}$ The conflict in results may be due to the higher proportion of obese patients in this study comparison to ours. There is also risk of reporting

Table3. Association of reflux symptoms with body mass and other GERD predictors

\begin{tabular}{|c|c|c|c|}
\hline BMI & $\begin{array}{l}\text { Symptoms } \\
(+)(112)\end{array}$ & $\begin{array}{l}\text { Symptoms } \\
(-)(15)\end{array}$ & $\begin{array}{l}P \\
\text { value }\end{array}$ \\
\hline$<25$ & 48 & 6 & \multirow{3}{*}{0.447} \\
\hline $25-30$ & 36 & 7 & \\
\hline$>30$ & 28 & 2 & \\
\hline $\begin{array}{l}\text { Age (continuous } \\
\text { variable) }\end{array}$ & 112 & 15 & 0.39 \\
\hline \multicolumn{4}{|l|}{ Age (categorical) } \\
\hline $18-40$ & 29 & 8 & \multirow{3}{*}{0.021} \\
\hline$>40-60$ & 51 & 7 & \\
\hline$>60$ & 32 & 0 & \\
\hline \multicolumn{4}{|l|}{ Sex } \\
\hline Male & 65 & 9 & \multirow{2}{*}{0.885} \\
\hline Female & 47 & 6 & \\
\hline Smoking & 66 & 5 & 0.566 \\
\hline Alcoholism & 40 & 2 & 0.084 \\
\hline Hiatus hernia & 33 & 5 & 0.769 \\
\hline \multicolumn{4}{|l|}{ Severity grade } \\
\hline Grade A & 23 & 2 & \multirow{4}{*}{0.697} \\
\hline Grade B & 47 & 5 & \\
\hline Grade C & 37 & 7 & \\
\hline Grade D & 5 & 1 & \\
\hline
\end{tabular}

under reflux symptoms if the patients are under anti reflux medication. Also, there is no exact definition and standard measure of the incidence of gastroesophageal reflux disease. Both endoscopy and 24 hour $\mathrm{pH}$ monitoring have significant limitations. Only about one third of patients with reflux disease have endoscopically detectable signs of reflux. ${ }^{19}$ Reflux symptoms are considered to be main tool of gastro-esophageal reflux disease. ${ }^{20,21}$ Analysis of the main symptoms, heartburn and regurgitation, is probably the most useful method for diagnosing this condition. ${ }^{19}$ Improper classification of GERD might have driven to lack of association in our 
study.

We also reported the clinical characteristics of the disease and its relation with the reflux symptoms. Severity grade was classified according to Los Angeles classification. ${ }^{14}$ Our study demonstrated no association between obesity and Los Angeles classification $^{14}$ grade of disease severity.

This study has been preformed with its some limitation which should be acknowledged. Several studies however reported the association of BMI and reflux symptoms, the comparatively small sample size in this study might have driven some of the study results difficult to be interpreted. In addition symptoms assessed by questionnaire in our study could have differed from others, leading our association to null.

\section{CONCLUSION}

Our study indicates that gastroesophageal reflux symptoms are not independently linked to obesity, defined by body mass index. However, Age factors were associated with the reflux symptoms. Further study in large population should explore the tendency of GERD symptoms towards BMI.

Acknowledgement: We thank institutional review board, NAMS Bir Hospital for ethical approval and department of medicine, gastroenterology for allowing data collection.

\section{REFERENCES}

1. El-Serag HB, Petersen NJ, Carter J, Graham DY, Richardson P, Genta RM, et al. Gastroesoph ageal reflux among different racial groups in the United States. Gastroenterology. 2004 Jun;126(7):1692-9.

2. Locke GR, Talley NJ, Fett SL, Zinsmeister AR, Melton LJ. Prevalence and clinical spectrum gastroesophageal reflux: a population-based study in Olmsted County, Minnesota. Gastroenterology. 1997 May;112(5):1448-56.

3. Chong V, Padam B, Hermanta R, Anand J. Gastrooesophageal reflux disorders among Nepalese residing in Southeast Asia. Med j Malaysia. 2013;68(3):234-8.

4. Henke CJ, Levin TR, Henning JM, Potter LP. Work loss costs due to peptic ulcer disease and gastroesophageal reflux disease in a health maintenance organization. Am J Gastroenterol. 2000 Mar;95(3):788-92.

5. Revicki DA, Wood M, Maton PN, Sorensen S. The impact of gastroesophageal reflux disease on healthrelated quality of life. Am J Med. 1998 Mar;104(3):2528.

6. Lagergren J, Bergstrom R, Lindgren A, Nyren O. Symptomatic gastroesophageal reflux as a risk factor for esophageal adenocarcinoma. N Engl J Med. 1999 Mar 18;340(11):825-31

7. Nilsson M, Johnsen R, Ye W, Hveem K, Lagergren J. Obesity and estrogen as risk factors for gastroesophageal reflux symptoms. JAMA. 2003 Jul 2;290(1):66-72.

8. Murray L, Johnston B, Lane A, Harvey I, Donovan J, Nair P, et al. Relationship between body mass and gastro -oesophageal reflux symptoms: The Bristol Helicobacter Project. Int J Epidemiol. 2003;32(4):645-50.

9. Andersen L, Jensen G. Risk factors for benign oesophageal disease in a random population sample. J Internal Med. 1991;230(1):5-10.
10. Diaz $\square$ Rubio M, Moreno $\square$ Elola $\square$ Olaso C, Rey E, Locke Gr, Rodriguez $\square$ Artalejo F. Symptoms of gastro oesophageal reflux: prevalence, severity, duration and associated factors in a Spanish population. Aliment Pharmacol Ther. 2004;19(1):95-105.

11. Lagergren J, Bergstrom R, Nyren O. No relation between body mass and gastro-oesophageal reflux symptoms in a Swedish population based study. Gut. 2000 Jul;47(1):269.

12. Locker GR, Talley NJ, Weaver AL, Zinsmeister AR, editors. A new questionnaire for gastroesophageal reflux disease. Mayo Clinic Proceedings; 1994: Elsevier.

13. Joint F, Organization WH. Energy and protein requirements: report of a Joint $\mathrm{FAO} / \mathrm{WHO} / \mathrm{UNU}$ Expert Consulatation; 1985.

14. Armstrong D, Bennett JR, Blum AL, Dent J, De Dombal $\mathrm{F}$, Galmiche J, et al. The endoscopic assessment of esophagitis: a progress report on observer agreement. Gastroenterology. 1996;111(1):85-92.

15. Lagergren J, Bergström R, Nyren O. No relation between body mass and gastro-oesophageal reflux symptoms in a Swedish population based study. Gut. 2000;47(1):26-9.

16. Lundell L, Ruth M, Sandberg N, Bove-Nielsen M. Does massive obesity promote abnormal gastroesophageal reflux? Dig Dis Sci. 1995;40(8):1632-5.

17. Kjellin A, Ramel S, Rössner S, Thor $K$. Gastroesophageal reflux in obese patients is not reduced by weight reduction. Scand J Gasteroenterol. 1996;31 (11):1047-51

18. El-Serag HB, Graham DY, Satia JA, Rabeneck L. Obesity is an independent risk factor for GERD symptoms and erosive esophagitis. Am J Gastroenterol. 2005;100(6):1243-50.

19. Dent J. Gastro-oesophageal reflux disease. Digestion. 1998;59(5):433-45.

20. Ter RB, Castell DO. Gastroesophageal reflux disease in patients with columnar-lined esophagus. Gastroenterol Clin North Am. 1997;26(3):549-63.

21. Revicki DA, Wood M, Wiklund I, Crawley J. Reliability and validity of the Gastrointestinal Symptom Rating Scale in patients with gastroesophageal reflux disease. Qual life Res. 1997;7(1):75-83. 